\title{
Nifedipine-Induced Gingival Hyperplasia: An Overlooked Adverse Effect
}

\section{Murat Eroglu $^{1 *}$, Omer Uz², Zafer Isilak ${ }^{1}$, Mehmet Tezcan ${ }^{1}$, Fethi Kilicaslan ${ }^{1}$ and Omer Yiginer}

${ }^{1}$ Department of Emergency Medicine, Gulhane Military Medical Academy Haydarpasa Teaching Hospital, 34668, Istanbul, Turkey ${ }^{2}$ Department of Cardiology, Gulhane Military Medical Academy Haydarpasa Teaching Hospital, 34668, Istanbul, Turkey

\begin{abstract}
Gingival hyperplasia is a common finding in a routine dental practice. Though it has many etiological factors, hyperplasia due to drugs which are administered to treat the systemic problems is of major problem which needs attention. Here, we present a case of nifedipine-induced gingival hyperplasia and draw the attention of clinicians.
\end{abstract}

Keywords: Gingival hyperplasia; Nifedipine; Side effect

\section{Introduction}

An increasing number of patients are being treated with multiple medications; some of these medications have an adverse reaction on the mouth and periodontal tissues. One of the unwanted side effects of these drugs is gingival hyperplasia [1]. Immunosuppressant drugs, antiepileptics, corticosteroids, non-steroidal anti-inflammatory drugs and calcium channel blockers can cause gingival hyperplasia [2]. It is a histomorphological alteration due to the side effects of a medication on the extracellular matrix [3] (Figure 1).

Nifedipine is one of the commonest antihypertensive drugs (calcium channel blockers) used to treat hypertension and some forms of angina [4]. Nifedipine inhibits calcium input directly from the cells of cardiac muscle and has a vasodilatory action that causes reduced arterial pressure [5]. Among calcium antagonists, it is the drug most commonly related to drug-induced gingival hyperplasia [6]. Nifedipine induced gingival hyperplasia was first reported in 1984; trials showed that prevalence varied between $14 \%$ and $83 \%[2,7,8]$. Despite the underlying pathophysiologic mechanism is unclear, histological studies showed numerous fibroblasts and increased glycosaminoglycan accumulation [7].

Here, we present a case with gingival hyperplasia as an overlooked adverse effect of nifedipine.

\section{Case Report}

A fifty-year-old female patient was admitted to the emergency department with the complaint of blood pressure irregularity. After first examination, the patient was consulted with cardiology clinic and nifedipine $30 \mathrm{mg} /$ day and atorvastatin $20 \mathrm{mg} /$ day was started with the diagnosis of hypertension and hyperlipidemia. Two months later, she was admitted to dental clinic because of partial dental prosthesis compatibility, halitosis and frequent bleeding of the gums. In addition, patient stated that feel constantly gums, teeth, and jaw pain. On examination, it was observed the presence of the 6-membered prosthesis including canine teeth and bright red gingival enlargement and hyperplasia involving both the upper and the lower jaws especially

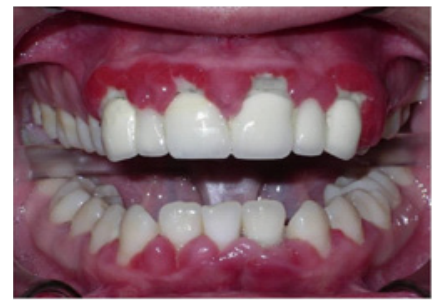

Figure 1: Gingival hyperplasia caused by nifedipine. in the anterior region. In addition, inflammatory and necrotic changes were seen in some localized area especially in upper jaw. Eventually, gingival hyperplasia was diagnosed. Etiological evaluation showed no abnormal background feature. Nifedipine, as the possible cause, was discontinued. After one and half month, gingival hyperplasia was completely recovered.

\section{Discussion}

Although gingival hyperplasia is a well known side effect of treatment with phenytoin, valproic acid, and cyclosporin, many physicians and cardiologists may not be aware that nifedipine, diltiazem, verapamil, and amlodipine have been similarly implicated [9].

Calcium antagonists like nifedipine block the input of calcium ions, thereby affecting homeostasis of collagen. The synthesis and degradation of the collagen being altered lead to the abnormal growth [10]. Factors like age, genetic predisposition, pharmacological actions, dose, plaque, and oral hygiene have been attributed for gingival enlargement in nifedipine-induced gingival hyperplasia. The age is indirectly proportional to the severity of the enlargement. Younger age people show more enlargements because they have greater fibroblastic metabolism and hormonal change than the elderly [11].

Various factors were attributed for the overgrowth of gingiva in nifedipine-induced hyperplasia, which include high plaque index (poor oral hygiene), high dose of the drug, genetic factors, individual susceptibility, and interaction between drugs and metabolites with the fibroblasts of gingival [12]. Nifedipine and atorvastatin are metabolized by the same enzyme, Cytochrome $\mathrm{P}_{450} 3 \mathrm{~A} 4$ [13]. In our case, concomitant use of nifedipine and atorvastatin may have decreased the metabolism of nifedipine and lead elevated serum nifedipine levels, which may increase the risk of development of gingival hyperplasia.

Drug induced gingival hyperplasia usually regresses after nifedipine is stopped. Regression may take a few months. Rigorous oral hygiene including scaling, gingival massage, and antiseptic washings to control plaque are thought to be an essential part of the management to prevent recurrence. Gingivectomy is sometimes required [9].

*Corresponding author: Dr. Murat Eroglu, GATA Haydarpaşa Eğitim Hastanes Acil Servis, 4668, Üsküdar, İstanbul, Turkey, Tel: 90-216-5422000-(3081); Fax: 90-216-3487880; E-mail: drmeroglu@yahoo.com

Received October 02, 2012; Accepted November 19, 2012; Published November 21, 2012

Citation: Eroglu M, Omer Uz, Isilak Z, Tezcan M, Kilicaslan F, et al. (2012) Nifedipine-Induced Gingival Hyperplasia: An Overlooked Adverse Effect. J Clin Case Rep 2:225. doi:10.4172/2165-7920.1000225

Copyright: @ 2012 Eroglu M, et al. This is an open-access article distributed unde the terms of the Creative Commons Attribution License, which permits unrestricted use, distribution, and reproduction in any medium, provided the original author and source are credited. 
Citation: Eroglu M, Omer Uz, Isilak Z, Tezcan M, Kilicaslan F, et al. (2012) Nifedipine-Induced Gingival Hyperplasia: An Overlooked Adverse Effect. J Clin Case Rep 2:225. doi:10.4172/2165-7920.1000225

Admitting to the dental clinics, not to the doctor who prescribed nifedipine, with the complaint of gingival hyperplasia or being ignored by the patients can conceal the frequency of this side effect induced by nifedipine and other calcium channel blockers. Furthermore, the patients admitted to the dentist with gingival hyperplasia can undergo unnecessary evaluation and approach.

In conclusion, our case is presented to draw the attention of clinicians to the calcium channel blocker induced gingival hyperplasia. We think that unnecessary evaluation and needless dental approaches can be prevented by close follow up of patients using calcium channel blockers.

\section{References}

1. Dongari-Bagtzoglou A; Research, Science and Therapy Committee, American Academy of Periodontology (2004) Drug-associated gingival enlargement. J Periodontol 75: 1424-1431.

2. Naidoo LC, Stephen LX (1999) Nifedipine-induced gingival hyperplasia: nonsurgical management of a patient. Spec Care Dentist 19: 29-34.

3. Matsumoto H, Noji I, Akimoto Y, Fujii A (2001) Comparative study of calciumchannel blockers on cell proliferation, DNA and collagen syntheses, and EGF receptors of cultured gingival fibroblasts derived from human nifedipine, nicardipine and nisoldipine responders. J Oral Sci 43: 261-268.

4. Barclay S, Thomason JM, Idle JR, Seymour RA (1992) The incidence and severity of nifedipine-induced gingival overgrowth. J Clin Periodontol 19: 311314.
5. Henry PD (1980) Comparative pharmacology of calcium antagonists: nifedipine, verapamil and diltiazem. Am J Cardiol 46: 1047-1058.

6. Butler RT, Kalkwarf KL, Kaldahl WB (1987) Drug-induced gingival hyperplasia phenytoin, cyclosporine, and nifedipine. J Am Dent Assoc 114: 56-60.

7. Missouris GG, Kalaitzidis RG, Cappuccio FP, MacGregor GA (2000) Gingival hyperplasia caused by calcium channel blockers. J Hum Hypertens 4: 155-156.

8. Routray SN, Mishra TK, Pattnaik UK, Satapathy C, Mishra CK, et al. (2003) Amlodipine-induced gingival hyperplasia. J Assoc Physicians India 51: 818819.

9. Ramsdale DR, Morris JL, Hardy P (1995) Gingival hyperplasia with nifedipine Br Heart J 73: 115

10. Lederman D, Lumerman H, Reuben S, Freedman PD (1984) Gingival hyperplasia associated with nifedipine therapy. Report of a case. Oral Surg Oral Med Oral Pathol 57: 620-622.

11. Lu HK, Chou HP, Li CL, Wang MY, Wang LF (2007) Stimulation of cells derived from nifedipine-induced gingival overgrowth with Porphyromonas gingivalis, lipopolysaccharide, and interleukin-1beta. J Dent Res 86: 1100-1104.

12. Sunil PM, Nalluswami JS, Sanghar SJ, Joseph I (2012) Nifedipine-induced gingival enlargement: Correlation with dose and oral hygiene. J Pharm Bioallied Sci 4: S191-S193.

13. Eliot LA, Jamali F (1999) Pharmacokinetics and pharmacodynamics of nifedipine in untreated and atorvastatin-treated hyperlipidemic rats. J Pharmacol Exp Ther 291: 188-193. 